Article

\title{
Exploring the Views of Dentists and Dental Support Staff Regarding Multiple Caries in Children
}

\author{
Wayne Richards, Teresa Filipponi *, Anne-Marie Coll and Jamal Ameen
}

check for updates

Citation: Richards, W.; Filipponi, T.; Coll, A.-M.; Ameen, J. Exploring the Views of Dentists and Dental Support Staff Regarding Multiple Caries in Children. Oral 2021, 1, 199-215. https://doi.org/10.3390/oral1030020

Academic Editors: W. Andrew Yeudall and Rachel Tham

Received: 20 March 2021

Accepted: 5 July 2021

Published: 9 July 2021

Publisher's Note: MDPI stays neutral with regard to jurisdictional claims in published maps and institutional affiliations.

Copyright: (c) 2021 by the authors. Licensee MDPI, Basel, Switzerland. This article is an open access article distributed under the terms and conditions of the Creative Commons Attribution (CC BY) license (https:// creativecommons.org/licenses/by/ $4.0 /)$.
Faculty of Life Sciences and Education, Glyntaff Campus, School of Care Sciences, University of South Wales, Pontypridd, Wales CF37 4BD, UK; wayne.richards@southwales.ac.uk (W.R.); anne-marie.coll@southwales.ac.uk (A.-M.C.); jamal.ameen@southwales.ac.uk (J.A.)

* Correspondence: teresa.filipponi@southwales.ac.uk; Tel.: +44-1443-482293

\begin{abstract}
This paper explores the reasons for multiple caries in children from the viewpoint of clinical practice, namely General Dental Practitioners (GDPs) and their teams, to identify obstacles to reducing inequalities in caries experience. The context of the research is the distribution of dental caries in UK communities where disease prevalence correlates with deprivation and these sub-groups are not attending for dental care on a regular basis. A focus group of dentists, along with individual interviews with dentists and dental support staff were chosen to explore the perceptions of GDPs, Dental Therapists, and Dental Nurses. The content analysis of the data highlighted six main themes. These included sugar, in terms of the amount, availability and the marketing of it; socioeconomic associations with dental caries experience; the dentists' role; the National Health Service (NHS) dental contract in terms of time-constraints in meeting targets and finally, the management of the child with multiple caries. This research suggests that there are possible barriers to the delivery of equitable care to populations. These include availability and access to GDPs along with the perceptions held by GDPs. Training aimed to develop a targeted behavioural approach towards deprived sub-groups is required in order to avoid unintended social exclusion.
\end{abstract}

Keywords: multiple caries; children; socioeconomic status; inequalities; stigmatisation; general dentist

\section{Introduction}

Oral diseases affect nearly 3.5 billion people worldwide with more than 530 million children suffering from tooth decay of primary teeth. This makes dental caries one of the most prevalent non-communicable (chronic) childhood diseases in the world [1]. In European countries there have been dramatic improvements in caries prevalence over previous decades [2]. However, caries prevalence in many European countries correlates with socioeconomic deprivation [2]. Northern European countries show lower caries prevalence than Southern and Eastern European countries [3]. In the United Kingdom (UK) epidemiological surveys show that $23 \%$ and $34 \%$ of 5-year-olds in England and Wales experience dental caries respectively $[4,5]$. The distribution of disease that is present is such that communities considered to be deprived tend to experience dental caries [5]. Steele (2015) states that dental caries is no longer a problem in higher socioeconomic populations in the UK [6]. Predominantly it will be children from deprived populations that will be experiencing multiple caries [6-8]. Moreover, these children are more likely to generate the need for general anaesthetics (GA) for tooth extraction [9].

Furthermore, Steele postulated in his 2015 BDA Anniversary Lecture that it is likely that the inequalities between higher and lower socioeconomic groups will persist based on the social determinants of health [10]. This reflects the support for an 'upstream' public health action as opposed to traditional individual 'downstream' behavioural approaches [11]. Batchelor (2012) considered population health and identified that upstream population approaches have the potential to increase social division when individual 
behaviour change is necessary within populations $[12,13]$. For example, water fluoridation will reduce the prevalence of caries in populations including the socioeconomically deprived [14-16]. However, the distribution continues to be skewed towards the deprived $[17,18]$. Individual behavioural factors impact on disease aetiology and unless the behaviours change, disease activity persists in individuals. This can be observed in the distribution of caries within communities in the UK [6]. Similar findings apply to the associations between obesity, dental caries and deprivation [19]. The World Health Organisation (WHO) suggests that excess calories from foods and drinks high in free sugars can lead to caries, being overweight and obesity. Thus, the intake of free sugars should be reduced to less than $5 \%$ of total energy intake [20].

Parents' attitudes and beliefs, education, socioeconomic status, culture and family functioning impact on oral health-related behaviours [21-28]. Health and social care structural systems have a potential to influence these variables and oral health behaviours [29]. Thus, the promotion to use non-dental personnel to deliver primary oral health prevention, for example using Health Visitors (registered nurses who work with children of pre-school age and their families) in the UK [30].

Higher socioeconomic groups utilise dental services regularly and asymptomatically while lower socioeconomic groups conversely utilise services irregularly and symptomatically [7,31-33]. The independent review of general dental services in England shows a flow chart demonstrating care pathways with individuals separated into those that choose ongoing continuing care pathways and those that do not [31]. It is clear that, in general, lower socioeconomic sub-groups are not attending for dental care on a regular basis.

In this context, without assuming that the reason for multiple caries is a lack of dental attendance, there is a gap between academic theory and reality. Theoretical models and approaches are documented in dental public health literature [34-36]. Levine, as early as 1974, published the Scientific Basis of Oral Health Education [34]. The need for regular attendance at general dental practice is a key primary prevention message to be promoted by dental professionals, stated in this document and subsequent editions [34,35]. It is therefore important to establish the relationship between decision-making within those attending regularly for dental care and those that are not if inroads are optimised to reduce these inequalities. The Scottish Forum for Public Heath Medicine states "Research is required to determine methods of improving dental attendance levels and to enable actual, rather than claimed attendance patterns to be established more accurately" [37]. Regular dental check-ups have been reported to be associated with better dental status $[38,39]$. The commonly held view that the poor oral health of poor people is explained by personal neglect has been challenged by some workers $[8,33,40,41]$. Therefore, critical reflection on the actions that determine a good level of oral health are needed in order to answer the question: are individuals choosing not to attend regularly or are there obstacles influencing choices?

Dental attendance is a required behaviour for appropriate individual advice regarding fluoride usage and sugar consumption if population sub-groups that are experiencing dental caries are to be reached and social divisions reduced. In this way the weakness identified by Batchelor [12] regarding upstream approaches is addressed.

The availability, accessibility and acceptability of care is paramount if the rhetorical promotion of ongoing care is to be manifested in reality. For over two decades access to dental services within the UK has been difficult, particularly for lower socioeconomic groups [42]. General dental practitioners and government continue to work towards a suitable and sustainable NHS Dental Contract that satisfies both parties [43,44]. There is a risk of stigmatising population sub-groups with targeted oral health promotion [13] therefore GDPs are ideally positioned to deliver prevention without stigmatising deprived sub-groups [45].

This paper aims to explore the views of GDP and dental support staff in regard to multiple caries in children in order to identify obstacles to reducing inequalities in caries experience. 


\section{Methods}

As the aim of this study was to engage GDPs and dental support staff about their perceptions, knowledge and practice in relation to multiple caries in children, a focus group as well as individual virtual interviews using Microsoft Teams were chosen primarily as the most appropriate method of exploring perceptions [46,47]. This methodological approach has been successfully used under a platform of the delivery of primary and secondary prevention by non-dental professionals which is promoted by government agencies [48]. In addition, the role of health-carers, teachers and parents has also been explored by the research team $[49,50]$.

\subsection{Sample}

The focus group comprised five GDPs who were midway through a part-time MSc in Clinical Endodontics and practising in different practices in South and West Wales. The five participants were emailed personally by one of the researchers, informed about the study and invited to participate. The response was positive. A mutually convenient date was arranged when the participants would be at the University for one of their study days. It was agreed that a focus group would take place at the end of the morning session. In accordance with the current literature on focus group size, a sample size of 5 is considered feasible [51,52]. In addition to the focus group, three general dental practices agreed to be involved in the research project. From the three practices, two dentists and four dental support staff representing dental therapists and dental nurses with further qualifications in oral health education, radiography and practice management agreed to be interviewed. They were also contacted by the same researcher in the same way and invited to participate in a virtual individual interview via Microsoft Teams.

\subsection{Data Collection and Analysis}

A 9-item focus group interview schedule was devised by the authors based on previously published research and a comprehensive review of the literature. The interview schedule was verified by a Specialist Dentist in Public Health and a Consultant in Dental Public Health. The focus group was undertaken in a quiet and well-ventilated board room in the university away from the general teaching areas. The individual interviews were done in the comfort of the respondent's home and were conducted on a day and at a time convenient to them. A facilitator and moderator were present for both methods of data collection. The key task of the facilitator was to administer the schedule of questions or topic guide. This is prepared to direct the discussion and cover key issues that the researcher wishes to examine during the focus group. The role of the moderator in the focus group and interviews was also invaluable and had had a positive impact on the richness of the data collection. The moderator was able to observe the participants' nonverbal reactions, make field notes, highlight areas of intense discussion as well as pauses, areas of agreement and disagreement all of which added to a rigorous and in-depth data analysis [46]. The focus group took approximately one hour, and the interviews took approximately $30 \mathrm{~min}$ to conduct.

A complete, unabridged transcription was produced for both the focus group and interviews and included all parts of words and hesitations which is an approach recommended by Bloor et al. [47]. The transcription was carried out by the facilitator within one week whilst the discussion was fresh in the researcher's mind. Initially, the recordings were played back several times to allow the researcher to feel confident that the transcription was an accurate and authentic record of what was said and for the main themes to emanate from the interview. This provided a closer connection between the interview and transcription which enhanced the content analysis.

The data analysis involved open coding in which keywords and phrases were highlighted which captured the essence of the participant's own words which were then coded into broader generic categories/themes. NVivo was used to assist and provide a more rigorous approach to this content analysis through the identification of nodes and sub- 
nodes. Investigator triangulation was established as all four members of the research team independently read and coded the transcripts before meeting to reach a consensus on the main themes.

Ethical approval was granted by the Low Risk Ethics Committee within the University faculty of Life Sciences and Education at the University of South Wales. The main ethical principles of informed consent, confidentiality, anonymity and data protection (GDPR 2016) were stated in both the information sheet and consent form and were upheld throughout the study.

\section{Results}

The content analysis of the data highlighted six main themes. These included sugar, in terms of the amount, availability and the marketing of it; socioeconomic associations with dental caries experience; the dentists' role which revolved around hands on activity as well as disease activity being associated with patient behaviours; the NHS Dental Contract in terms of time-constraints in meeting targets; patients' behaviours which involved some stereotyping and a perceived lack of knowledge and finally, the management of the child with multiple carious lesions. DF: Dentist Focus Group, DI: Dentist Individual Interview, DS: Dental Support Professional.

\subsection{Sugar}

There was a perception that the amount and availability of sugar contributed to caries levels in children.

DF 1 "sugar is everywhere, like you go anywhere, there is sugar like you go to like a hardware store, they have a sweets aisle"

DF 1 'there's so much research showing that sugar is the indicator, its not controversial at all, I mean decay is entirely preventable"

There was a level of acceptance that individuals in today's society are bombarded with high sugar consumption from marketing and selling of goods. In this context the group felt sorry for individuals in their fight to control the consumption of sugar thereby defending parents in their fight for health.

DF 1 "so you go through life saying, you actually have to make a conscious decision to refuse sugar every time you buy something"

Along with this, the concept of hidden sugars, particularly for foods marketed as healthy, played a considerable role in peoples' decision making towards the consumption of 'healthy' or 'safe' foods and drinks.

DF 2 "yeah no but there's all like you know fruit, dried fruit and its still high in sugar"

DI 1 "A lot of parents think that fruit is better. They are giving their children a lot of fruit now and that is maybe not the same amount of damage, but still some damage"

It was voiced that the individual's knowledge base would influence their choices and behaviours. Therefore, if people were unaware of the sugar content of foods/drinks and how they were consumed then this would be a contributory factor for high caries levels. How society was eating and drinking was also an issue that was identified. There was a perception that society had changed in its eating habits and that grazing had become an accepted way to feed in today's society.

DF 3 "I do think, you touched on something about mealtimes and things, lack of, society has changed, the dynamics of sitting down, family, having 3 meals, everyone is on the run, busy, somebody is rushing off here, the kids are rushing off to play netball, swimming, gymnastics or whatever it is, they're all on the go"

DF 3 "and lifestyle, its grazing throughout the day rather than meals, frequency of sugar throughout the day so even if its not necessarily high" 
With this in mind, individuals were thought to have a preference for an easy life and convenience foods.

DF 4 " ... it will have sugar and salt in cos that's how you add your flavours to it like the healthy foods, the low fat foods, for example, the fat is what gives you the flavour in food isn't it? And they take that out and they add sugar and salt to give you the flavour back"

\subsection{Socioeconomic Considerations}

Participants identified socioeconomic associations with caries experience, with low socioeconomic groups more likely to experience high levels of caries.

DF 3 "And families, you'd see, I used to work in Barry (deprived) and I would have a prescription pad and a referral pad for GA and virtually every single day of my working life $i$ was referring a kid for $G A^{\prime \prime}$

DF 5 "also generally like em, deprived areas I think we see more"

DF 4 "they've got dreadful, dreadful decay rates"

Cost considerations were also identified as an issue affecting the individual's decisionmaking regarding the foods to buy and consume.

DF 1 "It's a cost differential too, so like to buy a banana versus a Chomp bar, you know, food is so much cheaper. High calorie high sugar food is just cheap"

DS 2 "used to be that the high sugar foods were cheaper and easier to entertain. But obviously now with the sugar tax that has helped it a little bit"

Access to dental services was addressed with the fact that when available services were present, the parents did not take up the opportunity for care.

DF 1 "another thing about access is that its, from a dentist's point of view, like, sometimes the highest need patients are the ones who don't attend just by improving access doesn't mean that the target group will attend"

DF 5 "yeah that's something, they only come to the dentist when there's a problem and next time they come to you is when the kid needs another extraction or a filling"

DF 5 "I think a lot of people just go to the dentist when they've got a problem. They don't look at dentists from the point of improving oral health or the dentist can help us to you know look after our child's oral health, they just take the child or go themselves when they have a problem"

A preference for GA solutions to dental problems were voiced by the group with regard to treatment choices of lower socioeconomic groups.

DF 2 "but they find it quite a pleasant experience, the parents if they go to sleep, that's their preferred choice"

\subsection{Role and Experience}

The dynamic nature of caries as a process was not addressed directly within the discussions. However, it was stated that caries was preventable and how to achieve this through the control of behaviours. The oral health message was clearly understood by the group.

DF 1 "well the message is simple, like brush your teeth twice a day, use a fluoride toothpaste and stop snacking so its maybe we just need another public health campaign on $T V^{\prime \prime}$

Personal experience influenced their opinions. The perceived prevalence of caries was because of the patients they treated. It was clear that they associated patient behaviour with disease activity.

DF 3 "I found in my practice as in a middle class part of Cardiff and when I joined the practice 20 years ago, none of my kids had holes or any fillings" 
DI 1 "The lower socio economical classes or the higher not the middle is what I would say and the lower probably"

DF 4 "yeah so when I started 20 years ago kids ate sweets and got decay and then kinda go through the phases where, where, you don't have a lot of decay but you've got quite a lot of erosion from acids (agreement) and now you got getting massive amount of decay again because of the perceived, you've got to be a sporty person and the sports people"

DF 1 "interesting. In my experience I am in quite an affluent area as well and the vast majority of kids and patients who come to me don't have caries but if they do, it tends to be concentrated in certain families and there are a lot of caries in certain patients if they have caries in one tooth, they typically have it in 3 or 4"

DI 2 "All over, really. I don't think there's like many practices in Wales where you would go which didn't have high, relatively high caseloads of children with you know the high levels of caries"

It can be seen that experience has shown the dentists that behaviours, where mouth conditions are allowed to be caries active and lead to visible disease in individuals, are often related to family norms with regard eating habits.

DI 2 "Seeing families where for them it's normal for their children to have, as you say, a mouthful of dental caries... you say now we have to send this child for GA to have their teeth extracted... yeah I had to take your brother there"

Sadly, the dentists felt that they had little influence on individuals with regard to modifying their patients' behaviours.

DF 4 "I think we are a very small cog in a very big wheel"

DF 1 "I think my role is really limited, I've come full circle on that"

DF 1 “... but I also have patients who have high caries rate at the start of the treatment and a high caries rate 5 years later and yeah, I've the same message for them, it just bounces back, I think it is important to have conversations with patients but it's a limited effect, it won't work for everybody"

In order for successful behavioural interactions with patients, much emphasis was placed on the patient being motivated and receptive receivers rather than dentists as health promoters.

DF 1 "yeah I would love to be able to prevent decay in my patients and have the conversations with them but I'm sceptical as to how effective those conversations are I just think I agree with what you say, if you have more time you can speak to them about this but I'm not sure patients are receptive to it"

Patients were described as owning little responsibility in their own oral health and that they wanted an easy way out.

DF 4 "its easier for them to do a mouthwash"

DF 3 "they won't floss but they'll use a mouthwash" (Agreement)

DF 2 "convenience I think its that they are not very accepting that they are at fault, they want someone else to blame"

However, while dentists were negative regarding the effectiveness of prevention, dental support staff verbalised different views that were more positive.

DS2 "Um I do think I have a great deal (of influence), but think it's a little bit too late"

DS 4 "I think we have a very important role actually because if the caries rates need to come down in the, you know, children"

All discussion implied that the role of the dentist revolved around the delivery of hands on activity, even preventive activity fell into the category of hands on activity with the use of fluoride varnish. 
DS 2 "By the time they get to me because I'm not the one that is doing the normal check ups when there are no caries present. I'm the one that carries out the treatment, so although I can prevent it from happening in the future, I am not the one that can prevent it happening altogether"

DF 3 "Promotion by stealth, they bring these, we've had these things, like fluoride varnish"

DS 3 "Yeah, at the moment I'm currently working on doing a Fluoride application course"

When asked who should be responsible for organising oral health promotion; they suggested organisations such as the British Dental Association, Public Health Wales and Toothpaste companies should be responsible for this. Good methods of delivery were identified and included Design to Smile, Health Care Professionals like Health Visitors, Midwives and Teachers. Public campaigns using Television and Radio were suggested as an appropriate medium. Little responsibility was focused on dentists in their clinical role, with scepticism regarding the efficacy of oral health promotion. Again, dental support staff provided a contrary viewpoint emphasising team approaches and interdisciplinary involvement.

DS3 "Well, the dental team, ultimately led by the dentist"

DS4 "I think if they were getting oral health education, I think it would mainly come from an actual dental practice"

There was agreement with all that early attendance at the dentist should be encouraged and the value of primary prevention was recognised:

DF5 "as soon as they get their first tooth"

DF3 "and that's the rationale, its also good to bring them along even if its just sit in the chair and have a sticker sort of thing"

It was also discussed that the delivery of early attendance had been driven by guidelines from the Welsh Government.

DF 5 "We still get children 3 and a half, 4, 4years old and they are visiting the dentist for the first time"

DF 5 "We have been told that we should be seeing the kid with their first tooth but its not being told to the public"

Again, participants felt that whilst it was the responsibility of the dental team to deliver services on an individual level, there needed to be some kind of public campaign to support the directives too.

DF 134 "yeah and if they had a public health campaign and its going to cost them money that's why they try to get us to do for free with limited success"

\subsection{NHS Contract}

Funding within the NHS dental contract was a major cause for concern within the focus group. The contract of 2006 was target driven and that meant that target outcomes influenced decision-making for the dentists in terms of the type of patient that they needed to see to meet their target, otherwise their incomes would be reduced. From the perspective of the government these were unintended consequences and were highlighted by the group.

DF 4 "this contract, this 2006 contract was designed and set up to increase access to NHS dentistry but what it has resulted in doing is massively reducing access to NHS dentistry because dentists don't want, there is no incentive for dentists to take on new patients who have vast amounts of treatment required for the same amount of pay as you would get for treating a child who needs a filling versus a patient who needs 20 fillings, 6 extractions, how many teeth is that..." 
DF 4 "so this is the next point if you end up seeing lots of new patients doing huge amounts of work, in the end you use up all your time on them, you don't hit your targets so next year then they remove money from you and you don't earn you can't ever earn as much"

Time constraints were frequently used as an obstacle to the delivery of prevention and the NHS dental contract did not address this.

DF 3 "So even the new contract or these pilots that are going on, they're still driven by output and activity so there's still a financial gain, I know there's evidence that you, and they'll give you a tolerance allowing you more time to spend on the preventive side and use the team with therapists or health educators, I think that's very much people in ivory towers sort of thing"

Along with time constraints, the difficulties in managing some of the patients with the greatest need were identified, including non-compliance in terms of attendance.

DF 1 "If I opened my books in the morning I'd probably get lots of patients with no caries and the odd few that come in have lots of decay, who have maybe high anxiety who I can treat, might not return for treatment or if I can diagnose particularly a patient, a kid who has high caries, I would say that based on NICE guidance I would want to see him every 3 months, the next time, so often, the next time I see that kid would be in 18 months time when he would need another tooth that needs to come out"

DI 1 "the other thing is, was that the patients who are coming in then tend to be less regular attenders as well. So you get wasted appointment times then"

\subsection{Patients' Behaviours}

The context of discussions suggested that the group did not specifically highlight the behaviours related to disease activity to lower socioeconomic groups but individuals in society in general. Opinions were expressed regarding dental attendance:

DF 4 "yeah I think I remember a statistic when only $40 \%$ of the population only attends the dentist and that includes everyone who attends the dentist, emergencies, standard routine care otherwise you've got $60 \%$ who never really go ever"

There was much stereotyping of individuals with regard general attitude and behaviours that resulted in ill health and, by implication, oral ill health:

DF 3 "I think that's society, if you look at people going to the GP who are overweight, watch Jeremy Kyle, they've all got, smoke, have high blood pressure, diet, it's the whole package isn't it? It's not just teeth"

DF 5 "because they don't think teeth are important (agreement), its running in the generation that having a tooth out is not a big deal, so that's what they're teaching their children"

DS 2 "so obviously, either they just don't care or that they just can't take the information on board then"

DI 2 "Right as you say, these habits are very entrenched, aren't they? And they're difficult to break?"

Participants identified that lack of knowledge resulted in an unawareness of the behaviours required for oral health but also identified how difficult it was for them, as dentists, to help people when they were entrenched in a certain lifestyle:

DF 3 "so how do you educate somebody who comes in on crutches, is ridiculously overweight, on all sorts of medications, she smokes, drinks, goes and bets and tell them"

Furthermore, certain health behaviours that are promoted for general health contributed to oral health problems.

DF 1 "they do seem to be changing, like in young people, like that healthy body image now, while its not great for your teeth, there are kind of changes slightly about health" 
Parenting skills were identified as contributing to caries levels but, at the same time, parents were defended for practising behaviours that contributed to disease activity.

DF 5 "yeah, lack of knowledge from parents"

DF 1 "yeah like its very easy to say oh parenting levels are poor but its such a big problem, it can't be just down to the parents, like there's not that many bad parents on the planet"

DF 5 "a lot of parents do say oh, my kid doesn't eat any sweets but he eats a lot of fruits, that's another thing which is coming up, he eats a lot of fruits these days and is it the fruits that's not good for you? And the child's mouth will be full of caries and that's what you get from parents these days, he eats a lot of fruits, he doesn't eat any sugar"

\subsection{Management of Children with Multiple Caries}

The management of the child with multiple caries presented issues for the dental professionals from the viewpoint of the child experience and potential consequences for the long term. Restoring diseased teeth presented problems with management at the point of delivery with the possibility of distress for the child. Not restoring diseased teeth presented dissonance in that they were not doing what they perceived they should be doing as dentists.

DF 1 "another big difficulty too is particularly when you are dealing with kids and general anaesthetic is like anxiety and I find, I particularly found, in the last 10 years that every kid I take a tooth out on the majority come back with either phobias or real anxieties and it gets more difficult to do subsequent treatment"

Potential solutions were presented in the form of monitoring with prevention and minimising pain and infection:

DF 3 "I've always been lucky historically that I have been able to manage extensive decay by just trying to get them through until they exfoliate or fall out"

The use of GA either as a first or last resort was also identified as a possibility.

DS 3 "In the practice we will try and make it (GA) like the last resort, you know they will try and work on like prevention and maybe try and treat the child"

DS 2 "If they (GDPs) see multiple caries instead of trying to do this (prevention, monitoring and treatment) this is coming from previous work that I've done as a dental nurse. Instead of trying to treat, attempting to treat and sometimes referring to general anaesthesia too soon really"

The policy drive to reduce the number of GAs was problematic for the operators on many levels, the child's best interest was foremost.

DF 1 "and you try to avoid giving general anaesthetic to minimise this potential risk but you end up potentially then having to do a general anaesthetic and having to deal with the kid who will always have a phobia"

DI 2 "This system to try and bring the GA referral numbers down there, taking away the solution rather than the cause of the problem"

Many believed that the GA would be an unpleasant episode for the child resulting in difficult management issues for the future.

DS 2 "I know these children may have to go for general anaesthetics and this may affect them in their future life. You know they may be petrified of coming to the dentist in the future, there are difficulties with having general anaesthetic and that parents don't really think about you know from their general health and its not a completely risk free treatment and I don't think the parents think of the consequences to the child really"

Others recognised the need for GAs as a potential catalyst for behaviour change in the parent for whom cultural norms resulted in children with multiple caries.

DI 2 "You know we don't all live in the same world. And we don't have all the same choices open to us" 
DI 2 "I think we have very little influence over preventing these problems, but what we have been able to do historically is resolving very quickly"

Finally, a referral system of triage that replaced direct referral for GAs was not perceived to be in the best interest of the child and undermined the trust between the dentist and parent who would often have been a patient for a long time.

DS1 "you know, if the dentist knows what the patient needs, I feel like that should be listened to and just referred straight to the point it needs to, just be a referral that took place and then on to another place just feels a bit of a waste of time"

DI 2 "I find it insulting when you see a child you know you think, If you've been at practice for a long time and you know the family, but even without that you know you see a child and as a professional you realise that it is in this child's best interest to get this problem resolved quickly as possible in the way that causes the least trauma"

\section{Discussion}

Qualitative research is undertaken within time and context frames where attitudes and cultures change. This along with subjective elements from both participants and researchers makes reproducibility difficult. In addition, the generalizability of these findings has been limited by the small and somewhat homogeneous convenience sample. However, this does not devalue the findings of such research methods. What is important is how research methods and analytical approaches are described and reported. A triangulation of focus group and individual interviews strengthened the study methodologically and saturation of the findings was established. The focus group of GDPs were undertaking a higher degree for a specialist endodontic qualification therefore it could be that they were more interested in the delivery of hands on care compared with GDPs in the field. However, they were practising GDPs at the point when they were interviewed, and the views of GDP interviewees included similar themes. The GDPs and the dental support staff added further dimensions to the findings.

The fact that sugar was a theme within this research is of no surprise as the dental literature promotes the reduction of the overall intake and frequency of free sugars $[11,53]$. Evidence shows that the control of free sugars intake contributes to a reduction in the prevalence of dental caries [53-56]. However, there is some debate regarding whether the amount or the frequency of free sugars intake contributes to disease prevalence $[53,57]$. The Scientific Advisory Committee on Nutrition (SACN) were unable to determine the relationship between the two variables frequency and amount of free sugars and dental caries [58]. The SACN recommend the reduction of the total intake of free sugars and this is in line with the Common Risk Factor approach to health promotion [59]. Lagerweij and Van Loveren concluded "it is prudent to not only reduce the amount of sugar but even more so the frequency of sugar intake such that it is sustainable over a long period of time" [60].

This is an interesting finding as the research undertaken shows an underlying conflict within the participants studied. The concept of hidden sugars, a communication term that oral health educators use, was clearly visible as was the knowledge that fruits, dried fruits and other perceived healthy foods contained relatively high levels of sugar. Indeed, these foods contain a high level of free sugars which are the most important risk dietary factor for dental caries [20]. In addition to this, it was clearly stated that the frequency of consumption of foods contributed to dental caries levels. The tendency for grazing and the lack of mealtimes, along with the mantra of stop snacking was verbalised. Therefore, we can assume that the frequency of sugar intake is understood to be a causative factor in the development of caries. This is in line with current research evidence [13].

The ambiguity surrounding the debate between amount and frequency of sugar intake in dental caries development has been highlighted by Richards and Filipponi who, in an attempt to be specific in messaging, suggest leaving the mouth empty for a period of 2 hrs between episodes of food and/or drink intake [61]. This message would be clear to both high and low socioeconomic populations particularly as dental erosion is another condition that could result from frequent intake of acidic foods and drinks even if sugar free [62]. 
Another interesting point regarding this is the perception that the amount of sugar has an impact on high caries levels in the general community in today's society where $70.4 \%$ of Welsh 12 year olds and $66.6 \%$ of 5 year olds are caries free $[5,63]$.

Socioeconomic factors featured in the discussions surrounding high caries experience. It is clear that the participants understood that lower socioeconomic groups experienced higher levels of disease. However, it was not clear to what extent the group realised that high levels of dental caries were found mainly in deprived populations $[5,63]$. Some participants identified increased caries experience in patients where the practice serviced an affluent population. It could be that the experiences that individual practitioners received in their daily practice influenced their beliefs regarding epidemiological population experience of disease. Caries levels have decreased in children in the western world [1,64], Baelum suggested that the levels of disease are now low in adults too [65]. The number of band 1 and 2 treatments delivered by NHS GDPs in Wales were 62\% and 24\% in 2018-2019 supporting low treatment need in the patients attending general dental practice [66].

Cost was linked with social deprivation as a factor contributing to poor health. There was an opinion that sugary foods are cheap and that some fruit would be more expensive than confectionary. In reality a $250 \mathrm{~g}$ banana costs $20 \mathrm{p}$ [67] while a $45 \mathrm{~g}$ chocolate bar costs $75 \mathrm{p}$ [68]. One interviewee identified that sugar tax may have levelled out the cost differential [69]. The personal preferences of individuals in deprived sub-groups were highlighted, with symptomatic irregular attendance and GA seen as their preferred options. This was believed to be the case even in a situation where availability for, and access to, services was not problematic. This perception is shared by many within the dental community; GDPs involved in pilot contract schemes for example. They readily accept that some patients will choose urgent/emergency care over ongoing continuing care and that such services are adequately organised by the Local Health Board(s) [70,71]. Furthermore, the independent review of general dental services in England shows no qualification within the document as to how to facilitate influencing the choices irregular attenders make with regard to ongoing continuing care [31].

The dentists and dental support staff were clear on how to prevent dental caries with one participant saying that it is quite a simple overall message. The message voiced was in tune with current advice [36]. The link between behavioural choices and disease activity was clear from the data collected. However, their experiences as dental professionals differed between dentists and dental support staff. The dentists voiced opinions that it was difficult to influence changing patients' behaviours within their professional role. They felt that the individual patient needs to be motivated and want to change and they as dentists did not verbalise methods or skills to deliver active health promotion. In contrast, dental support staff were more positive regarding prevention. Other researchers have found similar opinions in dentists where higher socioeconomic groups were perceived to be more receptive and therefore more likely to receive oral health promotion [72,73]. Patients in general were seen to take little responsibility for actively controlling their disease and that an easy way out was preferred by patients. These experiences generated a negative view of the efficacy of preventive activity. Therefore, their role was that of someone providing hands on treatment and this spilled over into prevention with the delivery of fluoride varnish as preventive activity. Contract monitoring within the current systems in Wales include numbers of fluoride varnish applications as a measure of preventive activity [74]. Other professional groups were viewed as being responsible for oral health promotion and there was a need for joined up thinking with macro campaigns needed to reinforce the delivery of services through individual dental practice sites, such as the attendance for very young children at the dentist. Theoretical models of oral health promotion also suggest common macro, meso and micro messaging [75]. Aljafari et al. found similar findings from a qualitative study of general dental practitioners on promoting oral health in high-risk caries children [76]

The NHS contract was identified as having created a situation where patients with high needs and patients with difficult management issues such as anxiety were excluded 
from dental services. These were identified as unintended consequences of the new dental contract of 2006. Similar findings were reported by Aljafari et al. [76]. Contract monitoring by Primary Care Organisations seem to recognise the concept of dental fitness through the provision of treatment rather than staged care within a continuing care approach when evaluating individual contracts [77]. The lack of funding for prevention within the NHS contract was identified as a problem with primary prevention having been a directive from Government rather than in-house policy. Bloomfield recognised the need for change regarding funding and care provision in dentistry in the UK [78]. Since then, an expansion of service provision has been based on the concept of supply induced demand [79]. Holden et al. explored the views of Australian dentists, where $85 \%$ of dental care is provided under private contracts and highlights the concerns regarding the commercialisation of dentistry [80]. The authors identified how dentistry has become more systematically commercialised as a professional enterprise and moved away from its roots in medicine. They highlighted the distinction between a patient needing a filling to address dental caries (health need) and a patient requesting orthodontics or tooth whitening because their appearance does not conform to social norms (supply induced demand). Richards et al. documented the development of services in the UK over the last three decades [42]. The impact of service delivery on oral health and the balance between oral health and supply induced demand has been investigated in an ecological study in Wales in which the study showed improvements in oral health with persistent social inequalities [81].

Interestingly these high need groups were not specified as deprived sub-groups, rather those individuals with high dental needs. Similarly, the research has not seen an overt connection between patient behaviours and socioeconomic status on an individual basis, other than those reported earlier. This may be because the social make-up of the catchment areas they are servicing are relatively deprived. Richards et al. identified the fact that a practice situated in a deprived area does not always represent the deprivation profile of the area; often the practice profile is weighted towards higher socioeconomic groups [82]. Innate biases could be demonstrated with the focus group individuals remembering problematic patients as a greater portion of their patient base; they are then likely to overestimate the frequency of such patients [83]. In this situation there is a risk that stereotyping the general population when the burden of disease is in the most deprived sub-groups could disadvantage a proportion of the population that would respond to oral health education advice if it was offered. This may explain the differences in the distribution of disease between the most and least deprived local authorities in Wales. For example, Monmouth, an affluent unitary authority, having $0 \%$ of the most deprived $10 \%$ of the Welsh population and only $19.6 \%$ of the most deprived $50 \%$ of Wales. Yet, $25.9 \%$ of 12 -year olds experience caries and those with caries have a DMFT of 1.93 at 2016-7 [84].

The views regarding dental attendance were not founded on fact regarding service usage as attendance for the 2-year period ending September 2019 was 55.1\% excluding patients on private contracts [85]. On the one hand the group stereotyped individuals with a poor general attitude, while on the other hand they defended individuals through their lack of knowledge and parenting skills. This may reflect some internal dissonance in dental personnel as parents and their own difficulties in managing their children's behaviours such as sugar eating. The group found communications regarding prevention difficult, particularly with stereotypical patients. This could be a reflection of the skills they acquired while training. Neville and Waylen suggest that behavioural and social science skills should be fully integrated into the UK dental curriculum and not just offered as an 'add on' to the undergraduate programme [86].

The management of this patient group with multiple caries stimulated discussions surrounding GA provision and managing primary caries teeth. The management of caries in children has been a controversial issue for over a decade, to fill or not to fill deciduous teeth [87-90]. The dilemmas faced were clearly verbalised both in the focus group and as individual interviewees. Recently, a randomised controlled trial, the RECUR trial has shown how prevention using motivational interviewing delivered by dental nurses resulted 
in significantly reduced repeat general anaesthetic need [91]. The authors indicated that the outcomes had implications for changing paediatric dental practice internationally. Training and implementation of behavioural approaches such as Motivational Interviewing and opportunities for Dental Nurses to perform brief interventions are likely to make contacts with parents more effective in line with the focus on Making Every Contact Count (MECC) promoted by the Welsh Government in the context of general health [92]. The inappropriate use of GA for dental extractions was highlighted by one dental support staff member. This issue has resulted in a drive to reduce GAs in Wales [93,94], pathways have developed that involve triage with decisions that may be at odds with the referring dentist. This position generated discontent within the whole dental team. Chieng et al. reported that many of the children referred for triage and treatment failed to complete treatments based on restoring teeth [95]. There is a clear opportunity to use GAs to catalyse behaviour change [91]. One dentist made a clear point that the policy to reduce GAs was addressing taking away the solution (quick easy resolution of the child's problem) rather than the cause of the problem ([in] effective prevention). Milsom et al. suggested a staged approach to the management of client groups with high dental need in the context of continuing care and prevention [96]. Another randomised controlled trial, the FICTION trial, has shown that the management of primary caries teeth does not necessarily require the restoration of the teeth in the context of prevention [97]. Richards et al. described how the contract has developed so that deprived sub-groups have been excluded from dental services [42]. The sparse availability of paediatric specialists limits the expert service provision; hence, the GDPs remain the first call to respond to children with multiple caries [98]. However, this can be considered a limitation in the study, as specialists or paediatric dentists may offer relevant perspectives and approaches as compared with general providers.

\section{Conclusions}

The question was posed in the introduction, are individuals choosing not to attend for regular care or are there obstacles influencing choices? This research suggests that there are barriers to the delivery of equitable care to populations. These include the availability and access to care to GDPs due to contract constraints. In addition, the role perceptions held by the GDPs may contribute to barriers. Furthermore, the lack of access to paediatric dentists may limit the choices available to parents. These barriers need further quantitative investigation in order to address issues and develop services. Without these developments unintended social exclusion for deprived sub-groups may persist within populations in the UK. This could apply to many European countries and other low- and middle-income countries worldwide. Developing service policies to address the conflict between rewarding professionals for outcomes based on a medical model of health rather than a social model of health is needed in order to equalize the financial balance between health driven practice and supply induced demand practice. In this way, population coverage can be achieved.

While there are sound reasons for a population approach to oral health promotion, this research highlights the conflict between population and targeted approaches. For example, the common risk approach to sugar reduction and the ambiguity surrounding understanding cultural aspects of lower socioeconomic behaviours and sugar consumption. Training voids for dentists and their teams need to be identified and filled in clinical practice. This may facilitate the development of a targeted approach towards deprived sub-groups. Along with an overall population approach within high-income countries a targeted approach could maximise the effectiveness of oral health promotion. The management of multiple caries in children is an example where approaches need to be addressed.

Targeted approaches could be delivered within structures already present without the danger of stigmatising the sub-group. In the UK, these include primary prevention through non-dental personnel such as Health Visitors [30]. Also, the development of General Dental Services as is the case in Wales [43]. School toothbrushing promotion is yet another example of targeting specific sub-groups such as Childsmile in Scotland [99] and Design to Smile in 
Wales [100]. Within clinical practice, the development of General Dental Services as is the case in Wales is yet another example of an integrated approach [43]. This places equity as opposed to equality to the forefront.

Author Contributions: Conceptualization, W.R., T.F., A.-M.C. and J.A.; methodology and data collection, W.R., T.F. and A.-M.C.; investigation, T.F. and A.-M.C.; formal analysis: W.R., T.F., A.-M.C. and J.A.; writing—original draft preparation, W.R.; writing—review and editing, W.R., T.F., A.-M.C. and J.A. All authors have read and agreed to the published version of the manuscript.

Funding: This research received no external funding.

Institutional Review Board Statement: The study was conducted according to the guidelines of the Declaration of Helsinki, and approved by the Low Risk Ethics Committee, Faculty of Life Sciences and Education, University of South Wales (18TF110118; 5 October 2020).

Informed Consent Statement: Informed consent was obtained from all subjects involved in the study.

Acknowledgments: We would like to thank all the participants who gave their time to take part in the focus group and be interviewed for this study.

Conflicts of Interest: The authors declare no conflict of interest.

\section{References}

1. Peres, M.A.; Macpherson, L.M.D.; Weyant, R.J.; Daly, B.; Venturelli, R.; Mathur, M.R.; Listl, S.; Celeste, R.K.; Guarnizo-Herreño, C.C.; Kearns, C.; et al. Oral diseases: A global public health challenge. Lancet 2019, 394, 249-260. [CrossRef]

2. Patel, R. The State of Oral Health in Europe-Report Commissioned by the Platform for Better Oral Health in Europe. 2012. Available online: http:/ / www.oralhealthplatform.eu/wp-content/uploads/2015/09/Report-the-State-of-Oral-Health-in-Europe.pdf (accessed on 6 January 2021).

3. Zsuzsa, B.; Kovalecz, G.; Márton, S.; Gáll, T.; Mahrouseh, N.; Varga, O. Childhood caries management in the European Union: A cross-sectional study. Heliyon 2021, 7, e06198.

4. Dental Public Health Intelligence Team. National Dental Epidemiology Programme for England: Oral Health of Five-Year-Old Children 2017. In A Report on the Inequalities Found in the Prevalence and Severity of Dental Decay; Public Health England: London, UK, 2018.

5. Morgan, M.; Monaghan, N. Picture of Oral Health Dental Caries in 5 Year Olds (2015/2016); Cardiff University: Cardiff, UK, 2017.

6. Steele, J. Summer lecture: Looking to the future at the Anniversary Lecture. Br. Dent. J. 2015, 219. [CrossRef]

7. Jamieson, L.M.; Thomson, W.M. Adult oral health inequalities described using area-based and household-based socioeconomic status measures. J. Public Health Dent. 2006, 66, 104-109. [CrossRef]

8. Olley, R.; Hosey, M.; Renton, T.; Gallagher, J. Why are children still having preventable extractions under general anaesthetic? A service evaluation of the views of parents of a high caries rise group of children. Br. Dent. J. 2011, 210, E13. [CrossRef] [PubMed]

9. Lau, K.T.; John, J.; Eaton, K.A.; Keightley, A.J. Service evaluation of the paediatric dental general anaesthesia service in NHS Lothian. Br. Dent. J. 2020, 1-5. [CrossRef] [PubMed]

10. Marmot, M.; Bell, R. Social determinants and non-communicable diseases: Time for integrated action. BMJ $2019,364,1251$. [CrossRef]

11. Watt, R.G. From victim blaming to upstream action: Tackling the social determinants of oral health inequalities. Community Dent. Oral Epidemiol. 2007, 35, 1-11. [CrossRef] [PubMed]

12. Batchelor, P. What do we mean by population health? Community Dent. Oral Epidemiol. 2012, 40, 12-15. [CrossRef]

13. McClaren, L.; McIntyre, L.; Kirkpatrick, S. Rose's population strategy of prevention need not increase social inequalities in health. Int. J. Epidemiol. 2010, 39, 372-377. [CrossRef] [PubMed]

14. Jones, C.M.; Worthington, H. The relationship between water fluoridation and socioeconomic deprivation on tooth decay in 5-year-old children. Br. Dent. J. 1999, 186, 397-400. [CrossRef]

15. Riley, J.C.; Lennon, M.A.; Ellwood, R.P. The effect of water fluoridation and social inequalities on dental caries in 5-year-old children. Int. J. Epidemiol. 1999, 28, 300-305. [CrossRef]

16. McGrady, M.; Ellwood, R.; Maguire, A.; Goodwing, M.; Boothman, N.; Pretty, I. The association between social deprivation and the prevalence and severity of dental caries and fluorosis in population with and without water fluoridation. BMC Public Health 2012, 12, 1-17. [CrossRef] [PubMed]

17. Iheozor-Ejiofor, Z.; Worthington, H.V.; Walsh, T.; O’Malley, L.; Clarkson, J.E.; Macey, R.; Alam, R.; Tugwell, P.; Welch, V.; Glenny, A.M. Water fluoridation for the prevention of dental caries. Cochrane Database Syst. Rev. 2015, 6, CD010856. [CrossRef] [PubMed]

18. O'Mullane, D.; Whelton, H. Caries Prevalence in the Republic of Ireland. Int. Dent. J. 1994, 44, 387-391. [PubMed]

19. British Society of Paediatric Dentistry. Dental Caries and Obesity Must Be Tackled Together. Position Statements. 2020. Available online: https://www.bspd.co.uk/Professionals/Resources/Position-Statements (accessed on 20 December 2020). 
20. World Health Organisation (WHO). Guideline: Sugars Intake for Adults and Children; World Health Organization: Geneva, Switzerland, 2015.

21. Adair, P.M.; Pine, C.M.; Burnside, G.; Nicoll, A.D.; Gillett, A.; Anwar, S.; Broukal, Z.; Chestnutt, I.G.; Declerck, D.; Ping, F.X.; et al. Familial and cultural perceptions and beliefs of oral hygiene and dietary practices among ethnically and socio-economical diverse groups. Community Dent. Health 2004, 21, 102-111. [PubMed]

22. Saldūnaitè, K.; Bendoraitienè, E.A.; Slabšinskienè, E.; Vasiliauskienė, I.; Andruškevičienè, V.; Zūbienė, J. The role of parental education and socioeconomic status in dental caries prevention among Lithuanian children. Medicina 2014, 50, 156-161. [CrossRef] [PubMed]

23. Kumar, S.; Kroon, J.; Lalloo, R. A systematic review of the impact of parental socio- economic status and home environment characteristics on children's oral health related quality of life. Health Qual. Life Outcomes 2014, 12, 1-15. [CrossRef]

24. Kramer, P.F.; Chaffee, B.W.; Bertelli, A.E.; Ferreira, S.H.; Béria, J.U.; Feldens, C.A. Gains in children's dental health differ by socioeconomic position: Evidence of widening inequalities in southern Brazil. Int. J. Paediatr. Dent. 2015, 25, 383-392. [CrossRef]

25. Duijster, D.; Verrips, G.; Loveren, C. The role of family functioning in childhood dental caries. Community Dent. Oral Epidemiol. 2014, 42, 193-205. [CrossRef] [PubMed]

26. Kim, R.; Ok, Y.; Telleen, S. Predictors of the utilization of oral health services by children of low-income families in the United States: Beliefs, cost, or provider? J. Korean Acad. Nurs. 2004, 34, 1460-1467.

27. Hilton, I.V.; Stephen, S.; Barker, J.C.; Weintraub, J.A. Cultural factors and children's oral health care: A qualitative study of carers of young children. Community Dent. Oral Epidemiol. 2007, 35, 429-438. [CrossRef] [PubMed]

28. Nassani, M.Z.; Kay, E.J.; Al-Nahhal, T.I.; Oksayan, R.; Usmez, A.; Mohammadi, T.M. Is the value of oral health related to culture and environment or function and aesthetics? Community Dent. Health 2015, 32, 204-208.

29. Eskytè, I.; Gray-Burrows, K.A.; Owen, J.; Sykes-Muskett, B.; Pavitt, S.H.; West, R.; Marshman, Z.; Day, P.F. Organizational Barriers to Oral Health Conversations Between Health Visitors and Parents of Children Aged 9-12 Months Old. Front. Public Health 2021, 9, 578168. [CrossRef] [PubMed]

30. Welsh Government. An Overview of the Healthy Child Wales Programme. 2020. Available online: https://gov.wales/sites/ default/files / publications / 2020-12/an-overview-of-the-healthy-child-wales-programme.pdf (accessed on 20 December 2020).

31. Department of Health. NHS Dental Services in England. An Independent Review Led by Professor Jimmy Steele. 2009. Available online: http:/ / www.sigwales.org/wp-content/uploads/dh_101180.pdf (accessed on 20 December 2020).

32. Donaldson, A.N.; Everitt, B.; Newton, T.; Sherriff, M.; Bower, E. The effects of social class and dental attendance on oral health. J. Dent. Res. 2008, 87, 60-64. [CrossRef] [PubMed]

33. Sanders, A.E.; Spencer, A.J.; Slade, G.D. Evaluating the role of dental behaviour in oral health inequalities. Community Dent. Oral Epidemiol. 2006, 34, 71-79. [CrossRef]

34. Levine, R. The Scientific Basis of Oral Health Education, 1st ed.; Springer: Cham, Switzerland, 1974.

35. Levine, R.; Stillman-Lowe, C. The Scientific Basis of Oral Health Education, 8th ed.; BDJ Books: London, UK, 2019.

36. Public Health England. Delivering Better Oral Health: An Evidence-Based Toolkit for Prevention. 2017. Available online: https://assets.publishing.service.gov.uk/government/uploads/system/uploads/attachment_data/file/605266/Delivering_ better_oral_health.pdf (accessed on 3 January 2021).

37. Scottish Needs Assessment Programme (SNAP) Oral Health Network. Adult Oral Health. Scottish Forum for Public Health Medicine. 1997. Available online: https://www.scotphn.net/wp-content/uploads/2015/11/SNAP-Adult_Oral_Health.pdf (accessed on 7 July 2021).

38. Richards, W.; Ameen, J. The impact of dental attendance on oral health in a general dental practice. Br. Dent. J. 2003, 193, 697-702. [CrossRef]

39. Petersen, P.E.; Kjoller, M.; Christensen, L.B.; Krustrup, U. Changing dentate status of adults, use of dental health services, and achievement of national dental health goals in Denmark by the year 2000. J. Public Health Dent. 2004, 64, 127-135. [CrossRef]

40. Bedos, C.; Levine, A.; Brodeur, J.M. How people on social assistance perceive, experience, and improve oral health. J. Dent. Res. 2009, 88, 653-657. [CrossRef]

41. Richards, W.; Coll, A.M.; Filipponi, T. Missing links-A qualitative study investigating perceptions of teachers and parents of infant children, in two Welsh primary schools with different socioeconomic profiles, with regard to oral health. Oral Health Care 2017, 2, 2-7. [CrossRef]

42. Richards, W.; Filipponi, T.; Coll, A.M. General dental practice and improved oral health: Is there a win-win for both the professional establishment and government? Br. Dent. J. 2020, 228, 581-585. [CrossRef]

43. Welsh Government. Taking Oral Health Improvement and Dental Services Forward in Wales. A Framework Outlining Priorities for Dentistry and a Future Work Programme. 2017. Available online: https://gov.wales/sites/default/files/publications/2019-0 4/taking-oral-health-improvement-and-dental-services-forward-in-wales.pdf (accessed on 4 January 2021).

44. Brocklehurst, P.; Tickle, M.; Birch, S.; McDonald, R.; Walsh, T.; Goodwin, T.L.; Hill, H.; Howarth, E.; Donaldson, M.; O'Carolan, D.; et al. Impact of changing provider remuneration on NHS general dental practitioner services in Northern Ireland: A mixed-methods study. Health Serv. Deliv. Res. 2020, 8, 29-137. [CrossRef] [PubMed]

45. Richards, W. Does the General Dental Practitioner Have a Role in Tackling Oral Health Inequalities? Prim. Dent. J. 2013, 2, 58-63. [CrossRef]

46. Liamputtong, P. Focus Group Methodology: Principles and Practice; Sage Publications: Thousand Oaks, CA, USA, 2011. 
47. Bloor, M.; Frankland, J.; Thomas, M.; Robson, K. Focus Groups in Social Research, 1st ed.; Sage Publications: London, UK, 2001.

48. Welsh Government. Together for Health: A National Oral Health Plan for Wales, 2013-2018; Welsh Government: Wales, UK, 2013.

49. Coll, A.M.; Filipponi, T.; Richards, W. Health Visitors' and School Nurses' perceptions of promoting dental health in children. J. Health Visit. 2016, 4, 100-107. [CrossRef]

50. Filipponi, T.; Richards, W.; Coll, A.M. Oral health knowledge, perceptions and practices among parents and teachers from different geographical settings and socioeconomic profiles in South Wales, UK: A qualitative study. Br. Dent. J. 2018, 224, 517-522. [CrossRef] [PubMed]

51. Kruegar, R.A.; Casey, M.A. Focus Groups: A Practical Guide for Applied Research, 3rd ed.; Sage Publications: Thousand Oaks, CA, USA, 2009.

52. Kitzinger, J. Focus Group Research: Using group dynamics to explore perceptions, experiences and understandings. In Qualitative Research in Healthcare; Holloway, I., Ed.; Open University Press: Maidenhead, UK, 2005; pp. 56-70.

53. Moynihan, P.J.; Kelly, S.A. Effect on caries of restricting sugars intake: Systematic review to inform WHO guidelines. J. Dent. Res. 2014, 93, 8-18. [CrossRef]

54. Sheiham, A.; James, W.P. A reappraisal of the quantitative relationship between sugar intake and dental caries: The need for new criteria for developing goals for sugar intake. BMC Public Health 2014, 14, 1-8. [CrossRef]

55. Sheiham, A.; James, W.P. Diet and dental caries: The pivotal role of free sugars reemphasised. J. Dent. Res. 2015, 94, 1341-1347. [CrossRef] [PubMed]

56. White, D.A.; Tsakos, G.; Pitts, N.B.; Fuller, E.; Douglas, G.V.; Murray, J.J.; Steele, J.G. Adult Dental Health Survey 2009: Common oral health conditions and their impact on the population. Br. Dent. J. 2012, 213, 567-572. [CrossRef]

57. European Food Safety Authority (EFSA). Panel on Dietetic Products, Nutrition, and Allergies (NDA); Scientific Opinion on Dietary Reference Values for carbohydrates and dietary fibre. EFSA J. 2010, 8, 1462-1477.

58. Scientific Advisory on Nutrition (SCAN). Carbohydrates and Health; The Stationery Office (TSO): London, UK, 2015.

59. Sheiham, A.; Watt, R. The common risk factor approach: A rational basis for promoting oral health. Community Dent. Oral Epidemiol. 2000, 30, 241-247. [CrossRef] [PubMed]

60. Lagerweij, M.; van Loveren, C. Sugar and Dental Caries. In The Impact of Nutrition and Diet on Oral Health; Zohoori, F.V., Duckworth, R.M., Monogr, C.H., Eds.; Karger: Basel, Switzerland, 2020; pp. 68-76.

61. Richards, W.; Filipponi, T. An effective oral health promoting message? Br. Dent. J. 2011, 211, 511-516. [CrossRef] [PubMed]

62. Gambon, D.L.; Brand, H.S.; Veerman, E.C.I. Dental erosion in the 21st century: What is happening to nutritional habits and lifestyle in our society? Br. Dent. J. 2012, 213, 55-57. [CrossRef]

63. Morgan, M.; Monaghan, N. Picture of Oral Health 2018 Dental Epidemiological Survey of 12-Year-Old Children 2016-2017; Cardiff University/Public Health Wales: Cardiff, UK, 2018.

64. Petersen, P.E. The World Oral Health Report 2003: Continuous improvement of oral health in the 21st century-The approach of the WHO Global Oral Health Programme. Community Dent. Oral Epidemiol. 2003, 31, 3-24. [CrossRef]

65. Baelum, V. What is an appropriate caries diagnosis? Acta Odontol. Scand. 2010, 68, 65-79. [CrossRef]

66. Stats Wales. Courses of Treatment by Treatment Band, Patient Type, Local Health Board and Quarter. $2021 . \quad$ Available online: https://statswales.gov.wales/Catalogue/Health-and-Social-Care/General-Dental-Services/Current-Contract/ coursesoftreatment-by-treatmentband-patienttype-localhealthboard-quarter (accessed on 16 January 2021).

67. Office for National Statistics. Average Price Bananas, per Kg. 2021. Available online: https://www.ons.gov.uk/economy/ inflationandpriceindices/timeseries/czmv/mm23 (accessed on 8 March 2021).

68. Statista. Sales Price of Chocolate Bars* Per Kilogram Manufactured in the United Kingdom (UK) from 2008 to 2019. 2021. Available online: https: / / www.statista.com/statistics/481698/chocolate-bars-value-weight-in-the-united-kingdom-uk/ (accessed on 8 March 2021).

69. Government UK. Soft Drinks Industry Levy Comes into Effect. 2016. Available online: https://www.gov.uk/government/ publications / soft-drinks-industry-levy / soft-drinks-industry-levy (accessed on 9 February 2021).

70. Welsh Government. Welsh Dental Pilot Programme —End of Pilot Report; Welsh Government: Wales, UK, 2015.

71. Kilbride, K. Final Evaluation of Welsh Dental Pilots. Report to Welsh Government; Miller Research: Abergavenny, UK, $2015 ;$ pp. 1-51.

72. Threlfall, A.G.; Milsom, K.M.; Hunt, C.M.; Tickle, M.; Blinkhorn, A.S. Exploring the content and advice provided by general dental practitioners to help prevent caries in young children. Br. Dent. J. 2007, 202, E9. [CrossRef]

73. Threlfall, A.G.; Hunt, C.M.; Milsom, K.M.; Tickle, M.; Blinkhorn, A.S. Exploring factors that influence general dental practitioners when giving advice to help prevent caries in children. Br. Dent. J. 2007, 202, E10. [CrossRef] [PubMed]

74. General Dental Services Wales. Guidance for Dental Teams and Health Boards. Version 1. 2021. Available online: https: //dental.walesdeanery.org/sites/default/files/guide_to_q4_onwards.pdf (accessed on 18 February 2021).

75. Gift, H.C. Social factors in oral health promotion. In Oral Health Promotion; Schou, L., Blinkhorn, A.S., Eds.; Oxford University Press: London, UK, 1993; pp. 65-102.

76. Aljafari, A.K.; Gallagher, J.E.; Hosey, M.T. Failure on all fronts: General dental practitioners' views on promoting oral health in high caries risk children-A qualitative study. BMC Oral Health 2015, 15, 1-11. [CrossRef]

77. Welsh Government. Delivering NHS Dental Services More Effectively a Resource Pack for Health Boards and Dentists; Welsh Government: Wales, UK, 2015. 
78. Bloomfield, K. Fundamental Review of Dental Remuneration: Report of Sir Kenneth Bloomfield KCB; Her Majesty's Stationery Office (HMSO): London, UK, 1992.

79. Oliver, A. Reforming Public Sector Dentistry in the UK. Br. J. Health Care Manag. 2002, 8, 212-216. [CrossRef]

80. Holden, A.C.L.; Adam, L.; Thomson, W.M. Dentists' Perspectives on Commercial Practices in Private Dentistry. JDR Clin. Trans. Res. 2021. [CrossRef]

81. Richards, W.; Ameen, J.; Coll, A.M.; Filipponi, T. The balance between oral health feed and supply induced demand. Integr. J. Med. Sci. 2021, 8, 1-9. [CrossRef]

82. Richards, W.; Ameen, J.; Higgs, G. Adapting to change: Dental prescriptions. Br. J. Health Care Manag. 2008, 14, 500-504. [CrossRef]

83. Kay, E. How do we decide? Knowledge? Experience? Research? Evid. Dent. 2020, 21, 4. [CrossRef] [PubMed]

84. Welsh Government. Welsh Index of Multiple Deprivation (WIMD). 2019. Available online: https://gov.wales/welsh-indexmultiple-deprivation-full-index-update-ranks-2019 (accessed on 22 May 2020).

85. Stats Wales. NHS Patients Treated for Adults and Children by Local Health Board. 2021. Available online: https://statswales.gov. wales/Catalogue/Health-and-Social-Care/General-Dental-Services/Current-Contract/nhspatientstreatedforadultsandchildrenby-localhealthboard-patienttype (accessed on 5 January 2021).

86. Neville, P.; Waylen, A. Why UK dental education should take a greater interest in the behavioural and social sciences. Br. Dent. J. 2019, 227, 667-670. [CrossRef] [PubMed]

87. Milsom, K.; Tickle, M.; Blinkhorn, A.S. Dental pain and dental treatment of young children attending the general dental service. Br. Dent. J. 2002, 192, 280-284. [CrossRef] [PubMed]

88. Levine, R.S.; Pitts, N.B.; Nugent, Z.J. The fate of 1587 unrestored carious deciduous teeth: A retrospective general dental practice-based study from Northern England. Br. Dent. J. 2002, 193, 99-103. [CrossRef]

89. Pine, C.; Harris, R.; Burnside, G.; Merret, M.C.W. An investigation of the relationship between untreated decayed teeth and dental sepsis in 5-year-old children. Br. Dent. J. 2006, 200, 45-47. [CrossRef] [PubMed]

90. Richards, W. To fill or not to fill. Br. Dent. J. 2006, 200, 506. [CrossRef] [PubMed]

91. Pine, C.M.; Adair, P.M.; Burnside, G.; Brennan, L.; Sutton, L.; Edwards, R.T.; Ezeofor, V.; Albadri, S.; Curnow, M.M.; Deery, C.; et al. Dental RECUR Randomised trial to prevent caries recurrence in children. J. Dent. Res. 2020, 99, 168-174. [CrossRef]

92. Make Every Contact Count (MECC). 2021. Available online: https://mecc.publichealthnetwork.cymru/en/ (accessed on 2 March 2021).

93. Morgan, M. Child Dental General Dental Anaesthetics in Wales. Public Health Wales. 2019. Available online: https://gov.wales/ sites/default/ files / publications/2019-10/child-dental-general-anaesthetics-in-wales-2018-2019.pdf (accessed on 5 January 2021).

94. Bridgman, C.; Ashby, D.; Holloway, P. An investigation of the effects on children of tooth extraction under general anaesthesia in general dental practice. Br. Dent. J. 1999, 186, 245-247. [CrossRef]

95. Chieng, C.; Mohan, R.; Hill, V. Management of carious primary molars within the community dental setting in Wales: A retrospective observational study. Br. Dent. J. 2019, 226, 687-691. [CrossRef] [PubMed]

96. Milsom, K.M.; Jones, C.; Kearney-Mitchel, P.; Tickle, M. A comparative needs assessment of the dental health of adults attending dental access centres and general dental practices in Halton and St Helens and Warrington PCTs 2007. Br. Dent. J. 2009, 206, 257-261. [CrossRef]

97. Innes, N.P.; Clarkson, J.E.; Douglas, G.V.A.; Ryan, V.; Wilson, N.; Homer, T.; Marshman, Z.; McColl, E.; Vale, L.; Robertson, M.; et al. Child Caries Management: A Randomized Controlled Trial in Dental Practice. J. Dent. Res. 2020, 99, 36-43. [CrossRef]

98. Hunter, M.L.; Harrhy, L.E.; Morgan, M.Z. The United Kingdom's specialist workforce in paediatric dentistry: Current and future trends. Br. Dent. J. 2010, 208, 559-562. [CrossRef] [PubMed]

99. Macpherson, L.M.; Ball, G.E.; King, P.; Chalmers, K.; Gnich, W. Childsmile: The Child Oral Health Improvement Programme in Scotland. Prim. Dent. J. 2015, 4, 33-37. [CrossRef] [PubMed]

100. Iomhair, A.N.; Wilson, M.; Morgan, M. Ten years of Designed to Smile in Wales. BDJ Team 2020, 7, 12-15. [CrossRef] 